\title{
Overview of Digital Television Development Worldwide
}

\author{
YIYAN WU, FELLOW, IEEE, SHUJI HIRAKAWA, FELLOW, IEEE, \\ ULRICH H. REIMERS, SENIOR MEMBER, IEEE, AND JERRY WHITAKER, MEMBER, IEEE
}

\author{
Invited Paper
}

This special issue of the PROCEEDINGS OF THE IEEE presents a systematical and complete tutorial on digital television (DTV), produced by a team of DTV experts worldwide. This introductory paper puts the current DTV systems into perspective and explains the historical background and different evolution paths that each system took. The main focus is on terrestrial DTV systems, but satellite and cable DTV are also covered, as well as several other emerging services.

Keywords-Advanced Television Systems Committee (ATSC), digital broadcasting, digital television (DTV), digital video broadcasting (DVB), high definition TV (HDTV), integrated services digital broadcasting (ISDB).

\section{INTRODUCTION}

Television is probably the most cost-effective medium that informs, educates, and entertains the general public around the world. The television receiver is certainly the most popular home electronics device in the world. Based on the most recent data from the International Telecommunications Union (ITU), at the end of 2000, there were about 1.4 billion television sets in the world; many more than the number of fixed telephones ( 0.787 billion), cellular phones ( 0.75 billion), or personal computers ( 0.277 billion). Over the next 10-20 years, it is expected that these 1.4 billion analog TV sets will be replaced by digital sets, creating a multibillion dollar annual business for the broadcast equipment, consumer electronics, computer, and semiconductor industries.

Y. Wu is with the Communications Research Centre Canada, Ottawa, ON K2H 8S2, Canada (e-mail: yiyan.wu@ @crc.ca).

S. Hirakawa is with the Technology Planning Division, Toshiba Corporation, Tokyo 105-8001, Japan (e-mail: shuji.hirakawa@ toshiba.co.jp).

U. Reimers is with the Institute for Communications Technology, Braunschweig Technical University, Braunschweig D-38092, Germany (e-mail: u.reimers@tu-bs.de)

J. Whitaker is with the Advanced Television Systems Committee, Washington, DC 20006 USA (e-mail: jwhitaker@atsc.org).

Digital Object Identifier 10.1109/JPROC.2006.861000
Many countries have already started the transition from analog to digital television (DTV). DTV not only delivers interference and distortion-free audio and video signals; more importantly, it can do so while achieving much higher spectrum efficiency than analog television. DTV can also seamlessly interface with other communication systems, computer networks, and digital media, enabling datacasting and multimedia interactive services; it is a key element of the ongoing digital revolution leading toward the information society.

There have been few, if any, tutorials that comprehensively cover all the worldwide DTV systems. This PROCEEDINGS OF THE IEEE special issue on DTV has been produced by a team of experts in DTV from around the world who, for the first time, have jointly developed a complete and systematic tutorial series of papers. This introductory paper puts the various current DTV systems into perspective and explains the differing paths each system took in development. The main focus is on the terrestrial DTV systems, but satellite and cable DTV are also covered, as well as emerging services such as Internet Protocol TV (IPTV) and DTV to handheld devices.

\section{HISTORY OF TELEVISION RESEARCH AND DEVELOPMENT}

\section{A. Analog TV System Development History}

Many of the principles of television can be traced back to 19th-century work by European and North American inventors. The word "television" was first introduced in 1900 at the World's Fair in Paris, France, where the First International Congress of Electricity was held [1]. Television is a hybrid word, coming from both Greek and Latin. "Tele" is Greek for "far," while "vision" is from the Latin "visio," meaning "vision" or "sight." It is often abbreviated as TV. Research on television systems continued in the early 20th century, and by the 1920 s was well under way on both sides of the Atlantic. 
1) Monochrome Television: The early generations of television were mostly based on electromechanical systems. The display (TV screen) had a small motor with a spinning disc and a neon lamp, which worked together to give a blurry reddish-orange picture about half the size of a business card [2]. In 1926, in London, U.K., John Logie Baird demonstrated a 30-line system with such a display and an electromechanical optical scanner as a picture pickup device. Television broadcasting in the United Kingdom started with Baird's system in 1932. The British Broadcasting Corporation (BBC) television service started in 1936 with an on-air "bake-off" between an improved Baird 240-line mechanical system and a 405-line all-electronic system developed by the EMI and Marconi companies. In 1937, the 405-line monochrome system, known then as "high definition," was selected as the U.K. standard. Development also occurred in several other European countries, with a variety of TV systems used for transmissions. By 1950, most European broadcasters had selected a standard based on 625 scanning lines with 50 fields ( 25 frames) per second, later adopted in many other parts of the world, although for many years France used a system with 819 lines.

Meanwhile, in the United States, Vladimir Zworykin and Philo Farnsworth had worked independently on television research, with major breakthroughs during the 1920s and 1930s. Farnsworth transmitted the first electronically produced pictures in 1927, with a fully working system in 1934. Numerous stations had experimental transmissions during the 1930s, with a variety of mechanical and electronic systems. A 300-line all-electronic service was started in Los Angeles, CA, in 1936, and other stations soon followed. Major development work was undertaken by the Radio Corporation of America (RCA), and by the late 1930s the Radio Manufacturers Association (RMA), the forerunner of the Electronics Industries Association (EIA), had established industry standards [3]. The Federal Communications Commission (FCC) was not satisfied with the quality and level of performance of the RMA standard, and work on television development continued [4]. In 1942, the FCC adopted the work of the National Television System Committee (NTSC), and established a standard consisting of 525 scanning lines with 60 fields (30 frames) per second, which was also referred to as a "high definition" standard at that time. [5].

2) Color Television: Following on from earlier research, during the 1940s various color television systems were proposed and demonstrated in the United States. The first allelectronic color television system, backward compatible with the existing monochrome television system, was developed in the early 1950s and submitted by the second National Television System Committee to the FCC in 1953 [6]. The FCC approved the NTSC color TV standard on 17 December 1953 [7] and the first color live broadcast was of the Rose Parade in California on 1 January 1954. This standard was subsequently adopted by Canada, Mexico, Japan, and many other countries.

During the development of the NTSC color system, RCA had established a laboratory in Astoria, NY, three miles from the transmitter at the Empire State Building, where companies could bring receivers for testing. One night in April 1953, the RCA Princeton labs were conducting critical tests with test patterns, while receiver engineers asked repeatedly for live pictures. When the transmitter became available about 12:30 AM, the engineers requested that live talent and some colorful fruit be televised. George Brown of RCA noticed a can of blue paint nearby, and as a practical joke painted the bananas blue. The receiver engineers spent a half-hour unsuccessfully trying to get all the colors correct [8]. An apocryphal story tells of one manufacturer's crew at Astoria who were so certain of their receiver design that they turned off the set, and proclaimed, "They have the phase wrong at the transmitter," and went to a late dinner while waiting for the studio to correct their error. They never thought that the banana might be artificially made blue.

Color TV was not very successful in the United States until nearly a decade after its introduction. Few color TV sets were sold-they were expensive and did not perform well, and color programs were rare. Time magazine called color TV "the most resounding industrial flop of 1956" [2]. It was not until late 1960s that most TV programs were in color.

The countries of Europe delayed the adoption of a color television system, and in the years between 1953 and 1967, a number of alternative systems, compatible with the 625line, 50-field existing monochrome systems, were devised [9]. These had features intended to improve on NTSC, particularly to eliminate hue errors caused by phase errors of the color subcarrier in the transmission path.

An early system that received approval was one proposed by Henri de France of the Compagnie de Television of Paris. He suggested that the two pieces of coloring information (hue and saturation) could be transmitted as subcarrier modulation that is sequentially transmitted on alternate lines. Such an approach, designated as SECAM (SEquential Couleur Avec Memoire, for sequential color with memory) was developed and officially adopted by France and the USSR, and broadcast service began in France in 1967.

The implementation technique of a one-line delay element for SECAM led to the development, largely through the efforts of Walter Bruch of the Telefunken Company, of the phase alternation line (PAL) system. The line-by-line alternation of the phase of one of the color signal components averages any colorimetric distortions to give the correct value. The PAL system was adopted by numerous countries in continental Europe, as well as in the United Kingdom, and other countries around the world. Public broadcasting began in 1967 in Germany and the United Kingdom using two slightly different variants.

\section{B. Analog TV Enhancement Projects}

On the evolutionary path to fully digital TV systems, there were several projects to enhance and improve analog television using advanced analog and hybrid analog-digital technologies. Some of the projects worth mentioning are the Japan Broadcasting Corporation (NHK) HDTV [10] project in Japan, the Eureka EU 95 Project [11] and PALplus [12] in Europe, and Advanced Compatible Television in the United 

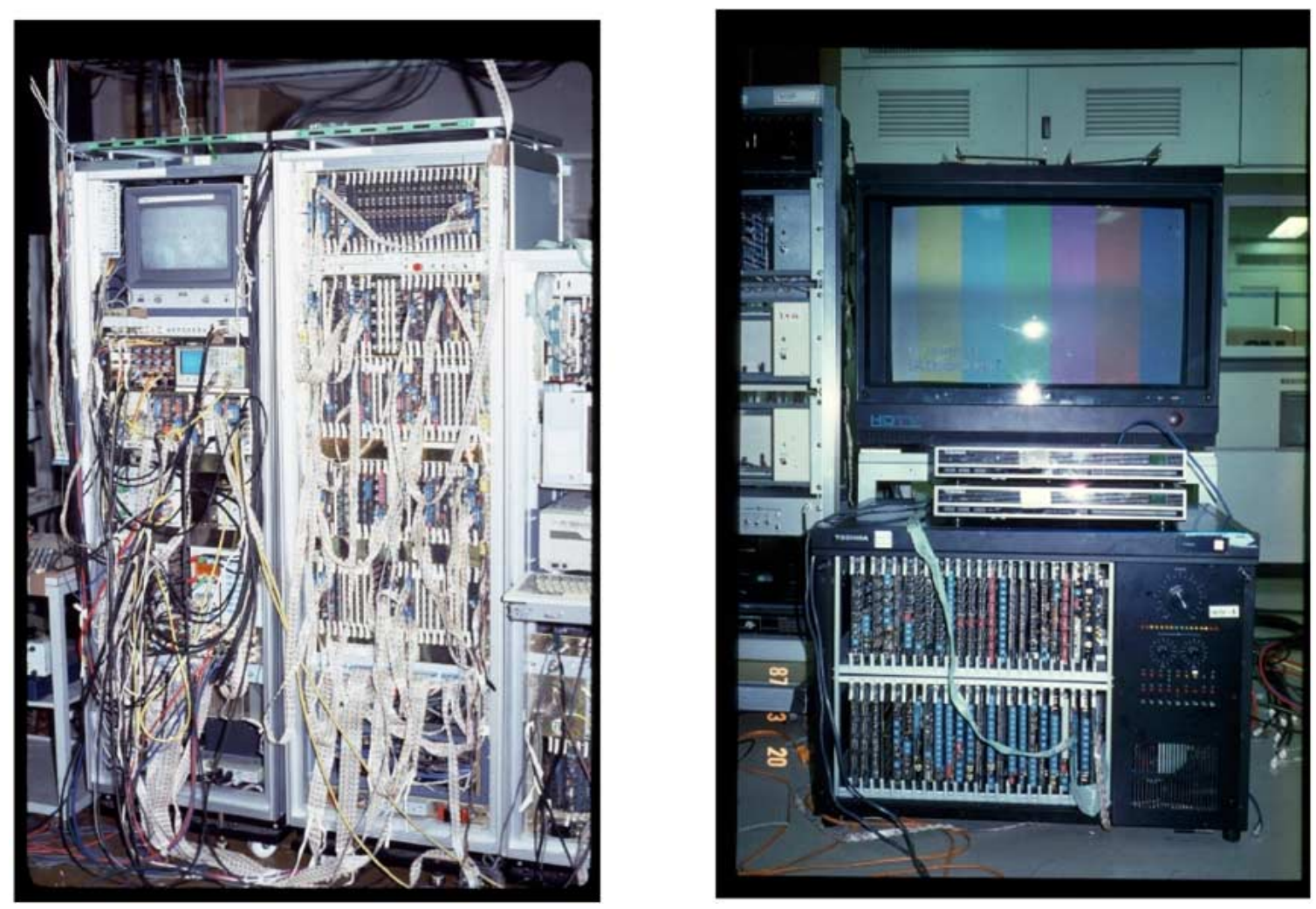

Fig. 1. MUSE hardware. (a) MUSE prototype modulator, 1986. (b) MUSE prototype receiver, 1986.

States [13]. They provided valuable experience for future DTV systems development.

1) NHK HDTV Projects: In 1964, the NHK Science and Technical Research Laboratories (STRL) started a research project on future television systems. This work began right after the successful live broadcasting of the 1964 Tokyo Summer Olympic Games to audiences around the world using satellite video transmission techniques developed by NHK. After five years of study, NHK established the concept of high definition television (HDTV) as a system suitable for viewing at roughly three times the picture height (compared to the five times picture height viewing distance suitable for the 525- and 625-line systems then in use around the world), having twice the horizontal and vertical (i.e., over 1000 scanning lines) resolution of conventional TV systems, and a wide aspect ratio. NHK then began research and development that was aimed at making HDTV a future broadcasting medium. By 1975, the 1125 -line/60-Hz scanning format was introduced based on the experimental studies that examined hardware feasibility and human vision properties [14].

In the early 1980s, NHK had developed most of the prototype equipment necessary for HDTV program production, including cameras, video tape recorders (VTRs), and display devices, largely based on analog techniques. In 1981, NHK conducted the first HDTV demonstration in the United States jointly with the Society of Motion Picture and Television Engineers (SMPTE), followed by a demonstration with the Columbia Broadcasting System (CBS) and the first demonstration in Europe with the European Broadcasting Union (EBU) in 1982.
In 1983, NHK developed a bandwidth reduction system called MUSE (which stands for "multi sub-Nyquist sampling encoding"). The system employed multiple sub-Nyquist sampling techniques in order to compress the original HDTV signal bandwidth from $30 \mathrm{MHz}$ down to $8.1 \mathrm{MHz}$. This would allow the transmission of the HDTV signal using one satellite transponder via frequency modulation (FM) of MUSE signal. The first trial of MUSE broadcast was at the Tsukuba Expo'85 in Japan (Fig. 1), which sparked worldwide efforts to develop practical HDTV transmission systems [15]. In 1989, MUSE satellite direct-to-home broadcasting started on an experimental basis. Currently, a single channel of daily MUSE broadcasting is still in operation. It is scheduled to move to digital broadcasting in 2007.

In the 1990s, HDTV production and distribution equipment made remarkable progress, driven by the need to supply programs for satellite MUSE broadcast services. The developments included CCD cameras, digital VTRs, camcorders, production and routing switchers, digital codecs for microwave links, and other equipment.

A new digital satellite broadcasting service was started in December 2000. The major broadcasters in Japan are broadcasting seven HDTV services via a direct broadcasting link using a broadcasting satellite (BS), allocated in the BSS planned band of 11.7-12.2 GHz. Moreover, terrestrial digital broadcasting started in the Tokyo, Osaka, and Nagoya metropolitan areas in December 2003. Both the satellite and the terrestrial systems are based on integrated services digital broadcasting (ISDB), which is HDTV-centered digital broadcasting augmented by various data services providing 
program-related information. In Japan, HDTV is considered indispensable for data services, since much of their content includes fine characters and/or graphics, which are readable only when displayed on a high definition screen.

Regarding international standardization activities, in 1972, Japan proposed a study program on HDTV to the CCIR (now ITU-R). The proposal was adopted by the CCIR Plenary Assembly in 1974, and since then, Japan has contributed many study results. One of the first parameters to be extensively debated was the aspect ratio of an HDTV system, which was originally conceived as being $5: 3$, offering somewhat wider pictures that the $4: 3$ aspect ratio of the 525- and 625-line television systems. International agreement was eventually achieved on a 16:9 aspect ratio, which more closely matches the $1.85: 1$ aspect ratio that is frequently used in $35-\mathrm{mm}$ film production.

Another key development was Japan's proposal of the $1125-$ line/ $60-\mathrm{Hz}$ format as the unified worldwide standard. The number of scanning lines was chosen to produce a similar level of complexity for format conversion to/from conventional TV systems with 525 or 625 lines and was based on the following criteria.

a) The number should be larger than 1050 , for a viewing distance of three to four screen heights.

b) It should be an odd number for interlace scanning.

c) Since the greatest common denominator between 525 and 625 is 25 , the total scanning lines should be a multiple of 25 .

Therefore, a "magic number" of 1125 was selected.

In 1997, Japan proposed that the two regionally proposed HDTV standards (1125- and 1250-line system proposed in Europe-see next section) be unified by introducing a common image format of 1080 active lines and 74.25-MHz sampling [16]. This resulted in the ITU-R Recommendation BT. 709-3. In 1999, the total number of scanning lines, which was the last outstanding parameter, was unanimously agreed upon to be 1125 , and a unified worldwide HDTV standard was finally realized. In 2000, ITU-R approved this HDTV system as the international studio standard, making it easier for international program exchange. This can be considered a great achievement by ITU-R Study Group 6 (former Study Group 11 ), which has worked on the issues over many years since the adoption of the Study Program in 1974.

2) Eureka EU 95 Project and PALplus: Since the 1960s, European countries have been using two analog color TV systems, namely, PAL and SECAM. Different variants of these two systems are in operation in different European countries. The move to HDTV was seen as an excellent opportunity to define a common system for the whole of Europe to replace PAL and SECAM, and to compete with the $1125-$ line/60-Hz HDTV production standards developed by Japan. This led to the creation of a research project funded by the European Union (EU) as part of its Eureka research framework. This project, code named EU 95, was supposed to develop a European solution for HDTV based upon the 1250-line/50-Hz system.

Multiplexed Analogue Components (MAC) was chosen as the fundamental technology underlying the development
[11]. C-MAC, D-MAC and D2-MAC were proposed as Standard Definition Television (SDTV) transmission standard variants and HD-MAC the SDTV backward compatible HDTV variant. All MAC systems were targeting cable and satellite distribution only, since, at that time, the terrestrial spectrum was seen as a resource that eventually would be freed from TV broadcasting services. In order to support the strategy underlying EU 95, in 1986 the European Commission issued what was called the MAC directive, in which it stated that all direct-to-home broadcast satellite (DBS) services using high-power satellites must use MAC or HD-MAC.

The HD-MAC system was successfully developed and HDTV pictures of impressive quality were shown in live satellite broadcasts from the Olympic games in Albertville, France (1992), Barcelona, Spain (1992), and Lillehammer, Norway (1994). However, none of the MAC systems succeeded in the European market place for a multiplicity of technical, commercial, and programming reasons.

In many countries of Europe, satellite direct-to-home broadcasting was very successfully introduced in the late 1980s, however, the successful services used an FM-modulated PAL signal for satellite distribution. This was possible, despite the existence of the "MAC directive," because the satellites used were considered telecommunications satellites - not DBS satellites - and, therefore, did not fall under that directive. The MAC systems were by-passed by the successful deployment of PAL satellite services and most satellite receiver manufacturers essentially ignored the MAC solutions altogether. The EU 95 project finished in 1995.

While HD-MAC was being developed as a transmission standard for cable and satellite distribution, a decision had to be taken about the future transmission technology for the terrestrial networks, which at that time delivered PAL and SECAM signals with 625 lines and an aspect ratio of $4: 3$. The planned introduction of HD-MAC was intended to lead to the deployment of production facilities providing HDTV pictures with an aspect ratio of $16: 9$, but the terrestrial TV networks would only be able to deliver image quality much inferior to the HD-MAC cable and satellite offerings-including a reduction of the number of TV lines displayed, which was in any case restricted by the 625 lines of the PAL standard. This reduction was a result of the "letterbox" approach that was chosen by many European broadcasters to overcome the incompatibility between $4: 3$ PAL displays and the 16:9 aspect ratio used for HDTV production. A solution was developed by the PALplus project, which started as a German "strategy group PAL" in 1988, and was formally created in early 1991 [12]. The group solved the aspect ratio problem by adding separately coded side panels to achieve 16:9 without reducing vertical resolution. PALplus was officially launched in Germany in 1995 and significant numbers of PALplus 16:9 receivers were sold-ironically despite the demise of HD-MAC. Key representatives of the PALplus project became the founders of digital video broadcasting (DVB), and a number of lessons learned by the members of this project were used in the creation of the DVB Project. 
3) U.S. Advanced Television: In 1987, U.S. broadcasters, watching the developments of MUSE and HD-MAC, as discussed in the following section, petitioned the FCC to establish an advanced television standard and allocate spectrum for over-the-air broadcasting. The FCC responded by establishing the Advisory Committee on Advanced Television Service (ACATS) to oversee the development of an advanced television system. Initially this group examined high definition systems largely based on analog technologies. The analog system proposals were, however, abandoned in favor of digital systems as described below.

\section{DTV SYSTEM DEVELOPMENT}

As indicated above, development of high definition and advanced television systems proceeded in parallel in the United States, Europe, and Japan. For various technical, organizational, and political reasons, this has resulted in multiple sets of DTV standards, applicable in different regions of the world.

Currently, there are three main DTV standard groups:

1) The Advanced Television Systems Committee (ATSC), a North America based DTV standards organization, which developed the ATSC terrestrial DTV series of standards. In addition, the North American digital cable TV standards now in use were developed separately, based on work done by Cable Television Laboratories (CableLabs) and largely codified by the Society of Cable Telecommunications Engineers (SCTE).

2) The DVB Project, a European based standards organization, which developed the DVB series of DTV standards, standardized by the European Telecommunication Standard Institute (ETSI).

3) The ISDB standards, a series of DTV standards developed and standardized by the Association of Radio Industries and Business (ARIB) and by the Japan Cable Television Engineering Association (JCTEA).

It is believed that China is currently developing another terrestrial DTV standard, which is expected to be finalized in 2006.

\section{A. ATSC and ACATS Process}

Following in the footsteps of the two successful NTSC committees that established the 525-line monochrome and color TV standards in the United States, the ATSC was formed in 1982 by the member organizations of the Joint Committee on InterSociety Coordination (JCIC). ${ }^{1}$ The purpose of the ATSC was to explore the need for and, where appropriate, to coordinate development of the documentation of advanced television systems. Documentation was understood to include voluntary technical standards, recommended practices, and engineering guidelines. ATSC member companies recognized that the prompt, efficient, and effective development of a coordinated set of standards

\footnotetext{
${ }^{1}$ The JCIC is currently composed of the Electronic Industries Association (EIA), the Institute of Electrical and Electronics Engineers (IEEE), the National Association of Broadcasters (NAB), the National Cable Television Association (NCTA), and the Society of Motion Picture and Television Engineers (SMPTE).
}

was essential to the future development of advanced television services.

Work on what would become the ATSC DTV system officially began in 1987, although the origins of HDTV can be traced back to the early 1980s with the first demonstrations of the NHK HDTV system. It was-in large part-the promise of HDTV that motivated the development of DTV.

1) ACATS: On 21 February 1987 a "Petition for Notice of Inquiry" was filed with the U.S. FCC by 58 broadcasting organizations and companies requesting that the commission initiate a proceeding to explore issues arising from the introduction of advanced television technologies and their possible impact on the television broadcasting service. At the time, it was generally believed that HDTV could not be broadcast using 6-MHz terrestrial channels. The broadcasting organizations were concerned that only alternative media would be able to deliver HDTV to the viewing public, placing terrestrial broadcasting at a severe disadvantage.

The FCC agreed this was a subject of utmost importance and initiated a proceeding (MM Docket no. 87-268) to consider the technical and public policy issues of advanced television systems. The commission subsequently established ACATS, consisting of 25 leaders of the television industry. Richard E. Wiley, a former chairman of the FCC, was named to lead the committee, with hundreds of industry volunteers serving on numerous Advisory Committee subcommittees. Canada and Mexico also participated in the ACATS process.

The Advisory Committee established subgroups to study the various issues concerning services, technical parameters, and testing mechanisms required to establish an advanced television system standard. It also established a system evaluation, test, and analysis process.

2) Development of the ATSC DTV Standard: Initially, 23 different systems were proposed to the Advisory Committee [17]. Mostly analog or hybrid analog/digital approaches, these systems ranged from "improved" systems, which worked within the parameters of the NTSC system to improve the quality of the video; to "enhanced" systems, which added additional information to the signal to provide an improved widescreen picture [13]; and finally to HDTV systems using two 6-MHz channels per program, which were completely new services with substantially higher resolution, a wider picture aspect ratio, and improved sound [18]. In January 1990, the FCC effectively rejected all of the proposed approaches by a policy announcement calling for: 1) establishing a full HDTV transmission standard; 2) using only a single 6-MHZ channel; and 3) locating it within the existing frequency bands allocated to analog TV broadcasting [19].

In response to the FCC's newly raised bar, a fundamental technological advance emerged when, in May 1990, General Instrument Corporation proposed the first all-digital HDTV. Their DigiCipher system proposal used the 1050i ("i” for interlaced scanning) video format, motion-compensated video compression, and QAM digital modulation [20], [21]. Within seven months, three additional all-digital HDTV systems had been proposed, emerging from their secret development programs at leading research laboratories. Advanced 


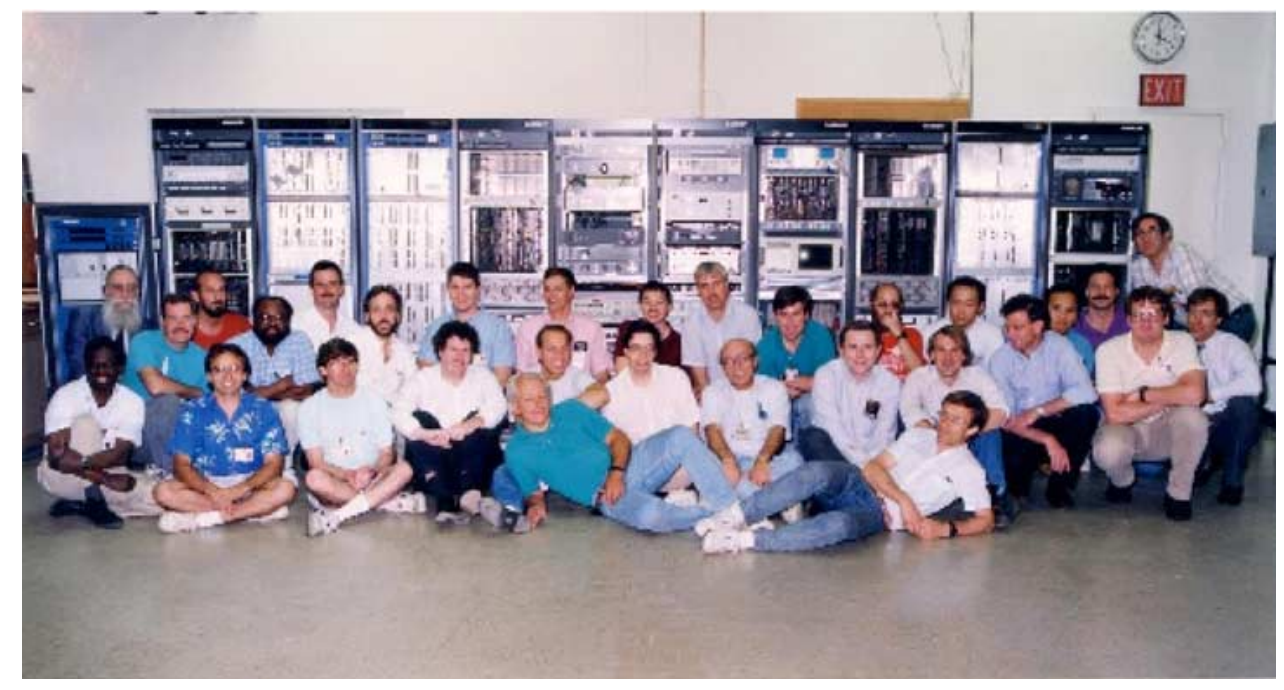

Fig. 2. The advanced digital HDTV prototype system (June 1992). Hardware racks (from left to right) are audio compression, video preprocessing, motion estimation, MPEG encoding, transport packet encoding, QAM modulators, RF channel simulator, QAM decoders, transport packet decoding, MPEG decoding and video postprocessing. Among the Sarnoff, Philips, and Thomson engineers pictured are Glenn Reitmeier, Carlo Basile, Terry Smith, and Aldo Cugnini.

Digital HDTV, proposed by Sarnoff, Thomson, Philips, and NBC, pioneered the use of multiple video formats, MPEG video compression, and packetized data transport [22], [23]. Digital Spectrum Compatible Television, proposed by Zenith and AT\&T, pioneered the use of the 720p progressive scan format and vestigial sideband digital modulation [24]. The Channel Compatible DigiCipher, proposed by General Instrument and the Massachusetts Institute of Technology (MIT), Cambridge, combined the use of the 720p format with QAM modulation [25]. Although the proponents highlighted their differences, all of the proposed systems were similar in their use of motion-compensated discrete cosine transform based video compression to achieve the required reduction in data rate necessary for transmission in a single 6-MHz channel [26].

By 1991, the number of competing system proposals had been reduced to six, including the four all-digital HDTV systems. The Advisory Committee developed extensive test procedures to evaluate the performance of the proposed systems and required the proponents to provide fully implemented real-time operating hardware for the testing phase of the process. From July 1991 to October 1992, the six systems were tested by three independent and neutral laboratories working together, following the detailed test procedures prescribed by the Advisory Committee [27] (Fig. 2).

The Advanced Television Test Center (ATTC), funded by the broadcasting and consumer electronics industries, conducted transmission performance testing and subjective tests using expert viewers [28]. CableLabs, a research and development consortium of cable television system operators, conducted an extensive series of cable transmission tests as well. The Advanced Television Evaluation Laboratory (ATEL) within the Canadian Communications Research Centre (CRC) conducted subjective assessment tests using nonexpert viewers [29].

In February 1993, a Special Panel of the Advisory Committee convened to review the results of the testing process, and - if possible - to choose a new transmission standard for terrestrial broadcast television to be recommended by the Advisory Committee to the FCC. After a week of deliberations, the Special Panel determined that there would be no further consideration of analog technology, and that based upon analysis of transmission system performance, an alldigital approach was both feasible and desirable. Although all of the all-digital systems performed well, each of them had one or more aspects that required further improvement.

The Special Panel recommended that the proponents of the four all-digital systems be authorized to implement certain modifications they had proposed, and that supplemental tests of these improvements be conducted. The Advisory Committee adopted this recommendation of the Special Panel, but also expressed its willingness to entertain a proposal by the remaining proponents for a single system that incorporated the best elements of the four all-digital systems [30].

a) The Grand Alliance: In response to this invitation, in May 1993, as an alternative to a second round of intense competitive testing, the proponents of the four all-digital systems formed the Digital HDTV Grand Alliance. The members of the Grand Alliance were AT\&T, General Instrument, North American Philips, MIT, Thomson Consumer Electronics, the David Sarnoff Research Center, and Zenith Electronics Corporation. In forming the Grand Alliance, the formerly competing proponents agreed to several key system principles, including: 1) accommodating both interlaced and progressive picture formats; 2) basing the video compression on the newly emerging MPEG-2 standard (see Section III-B1); and 3) utilizing a packetized data transport as part of a layered system architecture. However, many difficult choices remained, including whether or not to use bidirectional predicted B-frames, consideration of possible extensions to the MPEG syntax, which digital audio subsystem to use and which digital modulation technique to employ. After a thorough review of the Grand Alliance's initial proposal, the Advisory Committee worked, in col- 


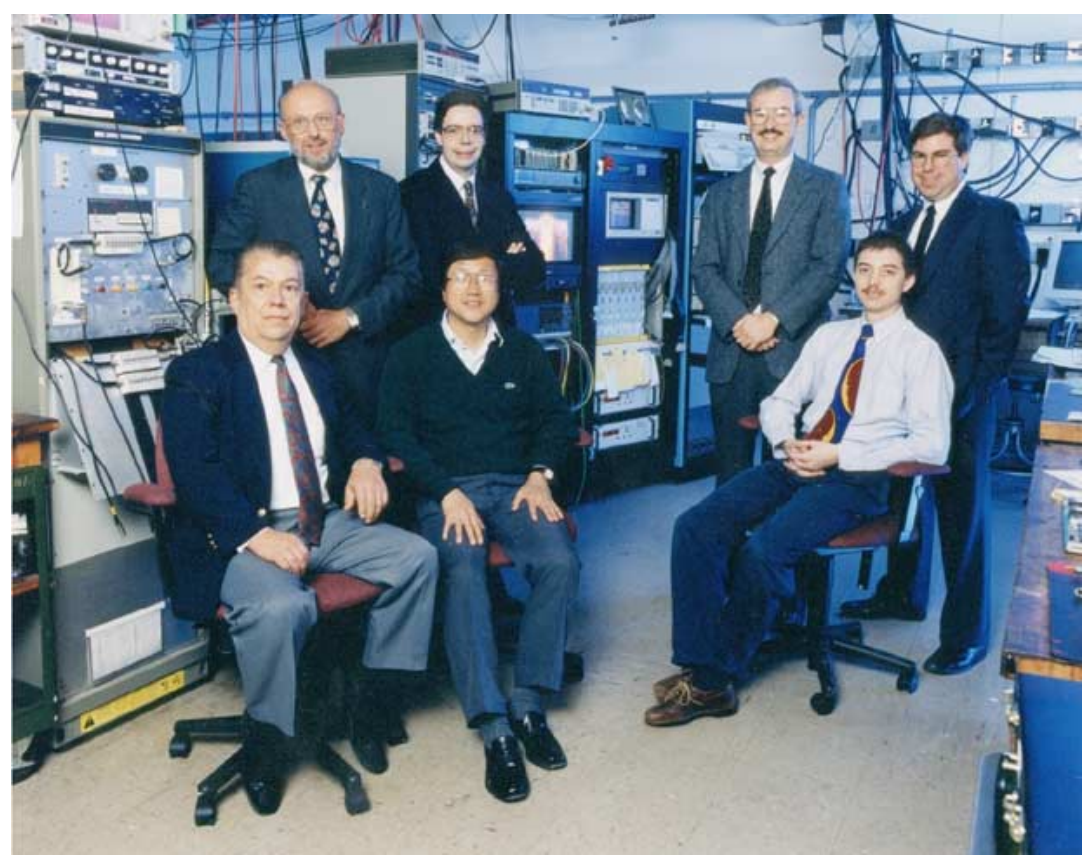

Fig. 3. The Grand Alliance HDTV prototype system (March 1995). Hardware racks shown (from left to right) are RF channel simulator, VSB demodulation, transport packet encoding, MPEG decoding and video postprocessing, video preprocessing and MPEG encoding, and system control computer. Grand Alliance technical leaders pictured are Wayne Luplow, Glenn Reitmeier, Bob Rast, Terry Smith, Ralph Cerbone, Jae Lim, and Aldo Cugnini.

laboration with the Grand Alliance during 1993 and early 1994, to finalize the design of the system, which eventually included the use of the $1920 \times 1080$ interlaced format and the $1280 \times 720$ progress format with square pixels, Dolby AC-3 (Dolby Digital) audio, and the use of 8-VSB modulation, which had demonstrated better performance than QAM during comparative transmission subsystem testing.

By 1994, the Grand Alliance companies proceeded to build a final prototype system based on specifications approved by the Advisory Committee [31]. The prototype Grand Alliance system was built in a modular fashion at various locations. The video encoder was built by AT\&T and General Instrument, the video decoder by Philips, the multichannel audio subsystem by Dolby Laboratories, the transport system by Thomson and Sarnoff, and the transmission system by Zenith. The complete system was integrated at Sarnoff Labs [32] (Fig. 3).

Testing of the complete Grand Alliance system began in April 1995 and was completed in August of that year.

The Advisory Committee testing of the Grand Alliance system was similar to that conducted for the four individual all-digital systems; however, additional tests were conducted to more fully evaluate the proposed system. These new tests included format conversions between the progressive and interlace modes (both directions) and compliance with the MPEG-2 video compression syntax. Subjective audio tests and long form viewing of video and audio programming were also conducted. Field tests were conducted in Charlotte, NC, utilizing the complete Grand Alliance system.

Working closely with the Advisory Committee throughout the U.S. DTV process, the ATSC was responsible for developing and documenting the detailed specifications for the ATV standard based on the Grand Alliance system [33]. In addition, the ATSC developed the industry consensus around several SDTV formats that were added to the Grand Alliance HDTV system to form a complete DTV standard. Among other things, these SDTV video formats provided for interoperability with existing television standards and supported the convergence of television and computing devices.

b) Documenting the DTV Standard: The ATSC assigned the work of documenting the advanced television system standards to specialist groups, dividing the work into five areas of interest:

- video, including input signal format and source coding;

- audio, including input signal format and source coding;

- transport, including data multiplex and channel coding;

- RF/transmission, including the modulation subsystem;

- receiver characteristics.

A steering committee consisting of the chairs of the five specialist groups, the chair and vice-chairs of the Technology Group on Distribution (T3), and liaison among the ATSC, the FCC, and ACATS was established to coordinate development of the documents.

Following completion of its work to document the U.S. ATV standard, the ATSC membership approved the specification as the ATSC Digital Television Standard (document number A/53) on 16 September 1995. On 28 November 1995, the FCC Advisory Committee issued its Final Report, providing the following conclusions.

- The Grand Alliance system meets the Committee's performance objectives and is better than any of the four original digital ATV systems.

- The Grand Alliance system is superior to any known alternative system.

- The ATSC Digital Television Standard fulfills all of the requirements for the U.S. ATV broadcasting standard. 
Accordingly, the Advisory Committee recommended to the FCC that the ATSC DTV Standard be adopted as the standard for digital terrestrial television broadcasting in the United States [34].

c) DTV Standard Adopted by the FCC: On 24 December 1996, the commission adopted the major elements of the ATSC Digital Television Standard, mandating its use for digital terrestrial television broadcasts in the United States. ${ }^{2}$

In 1997 the FCC adopted companion DTV rules assigning additional 6-MHz channels to approximately 1600 full-power broadcasters in the United States to permit them to offer digital terrestrial broadcast in parallel with their existing analog services during a transition period while consumers made the conversion to digital receivers or set-top boxes. The FCC also adopted a series of rules governing the transition to DTV, including a rather aggressive schedule for the transition. Under the FCC's timetable, stations in the largest U.S. cities were required to go on the air first with digital services, while stations in smaller cities would make the transition later.

Under the FCC's plan, more than half of the U.S. population would have access to terrestrial broadcast DTV signals within the first year, all commercial stations would have to be on the air within five years, and all public TV stations would have to be on the air within six years. Analog broadcasts were planned to cease after nine years (on 31 December 2006), assuming that the public had embraced digital TV in adequate numbers by that time. Part of the FCC's motivation in mandating a rapid deployment of digital TV was to hasten the day when it could recapture $108 \mathrm{MHz}$ of invaluable nationwide spectrum that would be freed up by the use of more spectrum-efficient DTV technology.

In accordance with the FCC plan, DTV service was launched in the United States on 1 November 1998, and more than 50 percent of the U.S. population had access to terrestrial DTV signals within one year. By 1 March 2003, there were more than 750 DTV stations on the air in the United States, and nearly 5 million DTV displays had been sold. By 1 March 2005, there were nearly 1400 DTV stations on the air and over 16 million DTV displays had been sold, including over 2.5 million with integrated ATSC tuners. According to CEA data, consumer adoption of HDTV in the United States is occurring at roughly twice the rate as the adoption of color TV.

The ATSC DTV Standard was submitted to Task Group 11/3 of the ITU-R, and in 1997 it was included as System A in ITU Recommendations BT.1300 and BT.1306.

3) Ongoing Work of the ATSC: Since the primary ATSC DTV Standard was adopted in 1995, the ATSC has conducted a wide-ranging program for developing supplemental DTV and DTV-related standards, and for addressing implementation issues that have arisen in the countries that have adopted the ATSC DTV Standard. Highlights of this work include a standard for program and system infor-

\footnotetext{
${ }^{2}$ The FCC did not mandate use of the specific HDTV and SDTV video formats contained in the ATSC standard, but these formats have been widely adopted on a voluntary basis by broadcasters and professional equipment and receiver manufacturers.
}

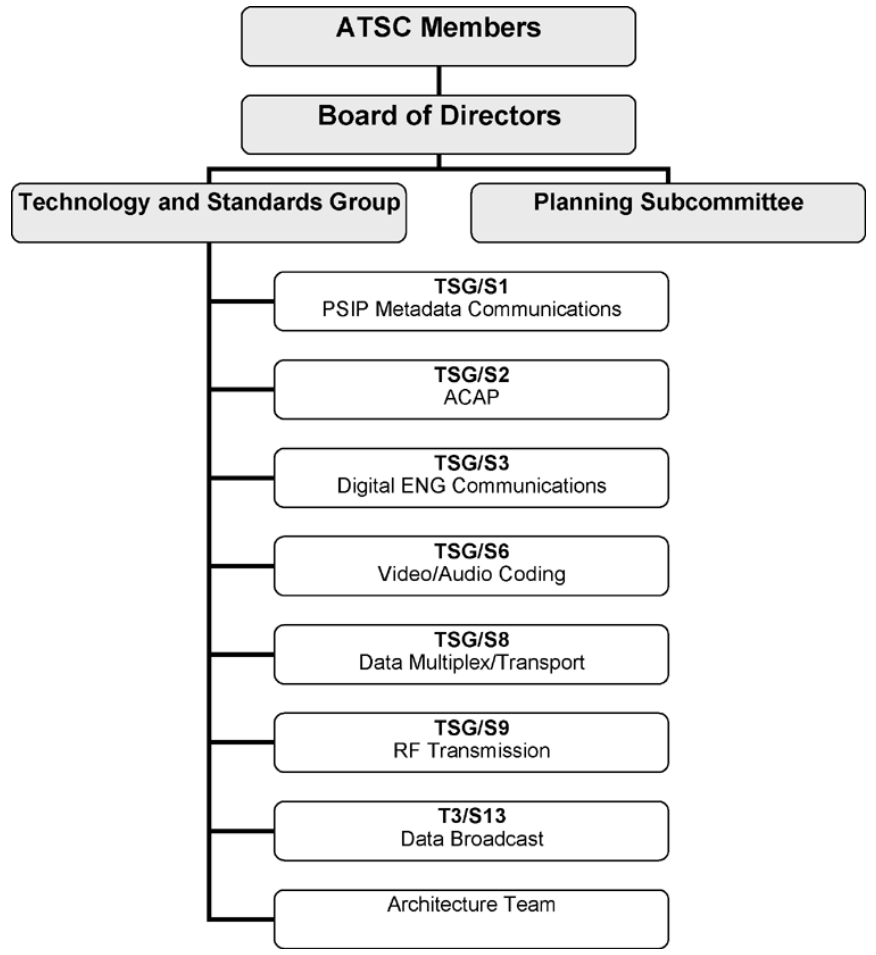

Fig. 4. Organizational chart of the ATSC.

mation protocol (PSIP), a conditional access standard to permit restricted or pay services, a suite of data broadcasting standards, a standardized software environment for digital receivers, a standard for distributed transmitter synchronization, a standard for satellite contribution and distribution services, and a standard for direct-to-home satellite services.

All segments of the television industry in North America and elsewhere are now represented within the ATSC, including broadcasters, cable companies, satellite service providers, consumer and professional equipment manufacturers, computer and telecommunications companies, and motion picture and other content providers. A current organizational illustration of the ATSC is given in Fig. 4. A Board of Directors, formed of members of the parent committee, manages the overall activities and directions of the ATSC. Two main subcommittees exist:

- the Technology and Standards Group (TSG);

- the Planning Committee (PC).

From time to time, the board can establish one or more task force groups to address specific items. Within the TSG structure, specialist groups are organized into specific areas of interest. Ad hoc groups may be formed for specific issues or projects.

4) Satellite and Cable Delivery of DTV Services in North America: It should be mentioned that the terrestrial broadcasting is no longer the only method for delivery of DTV services. In North America today, a large percentage of households are serviced by digital cable and digital satellite direct-to-home (DTH) systems. There are two papers entitled "Carriage of Digital Video and Other Services by Cable in North America" and "Satellite Direct-To-Home" 


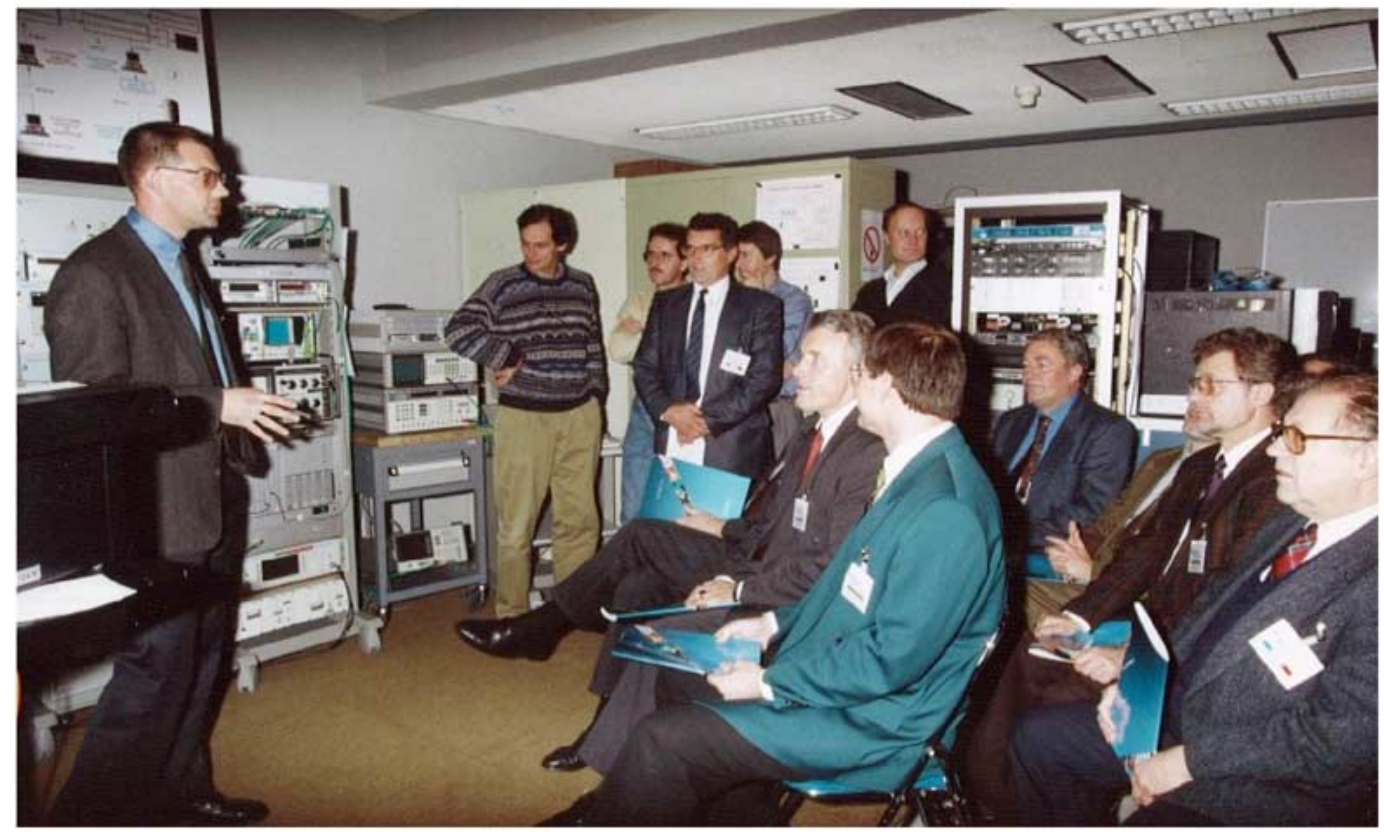

Fig. 5. CCETT STERNE Project demonstration during the Montreux Television Symposium 1993. Launched in 1991 in the CCETT laboratories in France, the STERNE project was aimed at showing the ability of OFDM for DTV terrestrial broadcasting. An 8K FFT modem was built and two demonstrations were presented at Montreux 1993: a digital transmission to a portable receiver and a multiplex of encrypted programs. In the picture, Philippe Bernard, Manager of the STERNE project, is demonstrating DTV to a group of visitors in Rennes, France, in the presence of Daniel Pommier, Head of CCETT and one of the OFDM inventors.

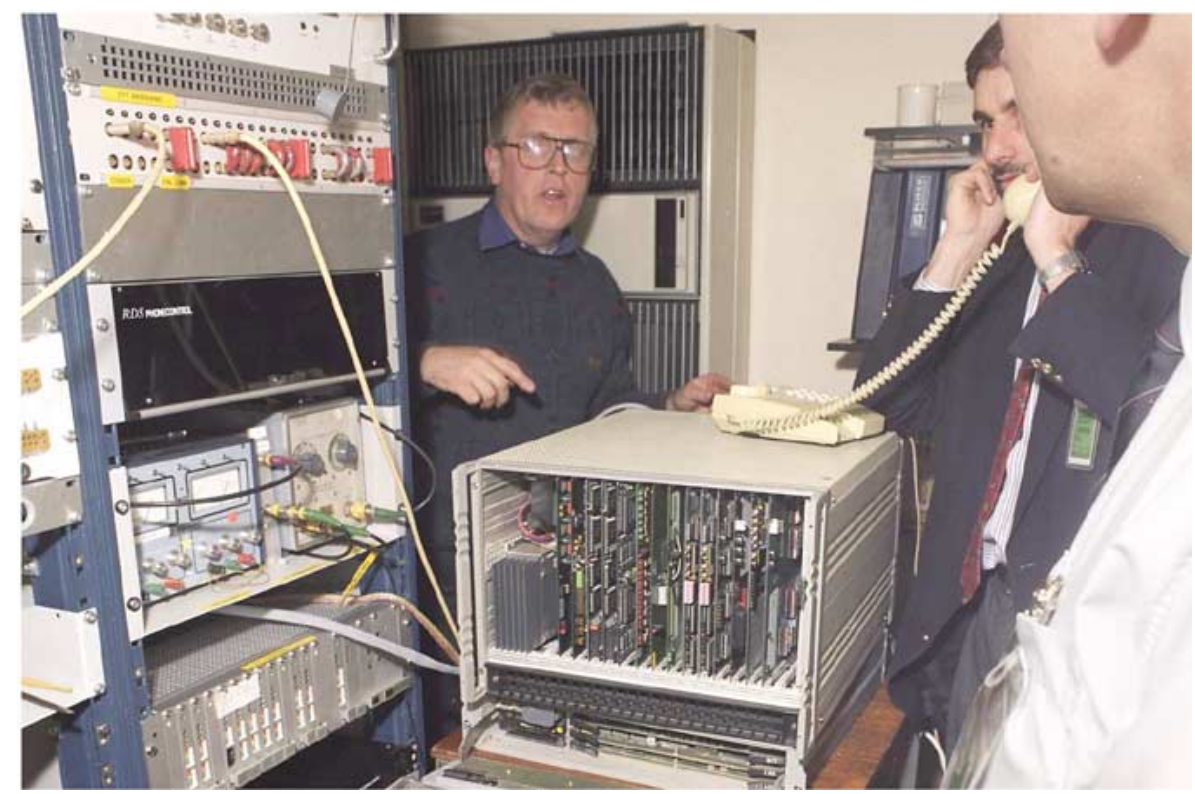

Fig. 6. BBC DVB-T prototype modulator and multiplexer at the Crystal Palace transmitter site in South London in 1996. The system was built for the first DVB-T live transmission. The rack in the center is the BBC DVB-T modulator (from left to right: Nick Tanton, Mark Maddocks, and Chris Clarke).

in this special issue, which provide detailed technical information on digital cable and digital satellite systems in North America.

\section{B. DVB Process}

1) DVB History and Organization: The DVB Project is the focal point of the development of DTV for many countries around the world [35] (Figs. 5 and 6). It was founded in 1993 and, as of late 2005, has about 270 member organizations from 32 countries. The DVB Project was preceded by the
European Launching Group (ELG). The start of DVB, as it is usually called, is a direct consequence of the experience that a number of European partners had gained in the PALplus project in the late 1980s and the early 1990s. Some key lessons learned in PALplus led to the following rules, which were incorporated in the statutes of the DVB Project.

1) Each DVB member has to pay its own cost and a moderate annual fee to support some DVB activities. DVB will not ask for funding by third parties. 


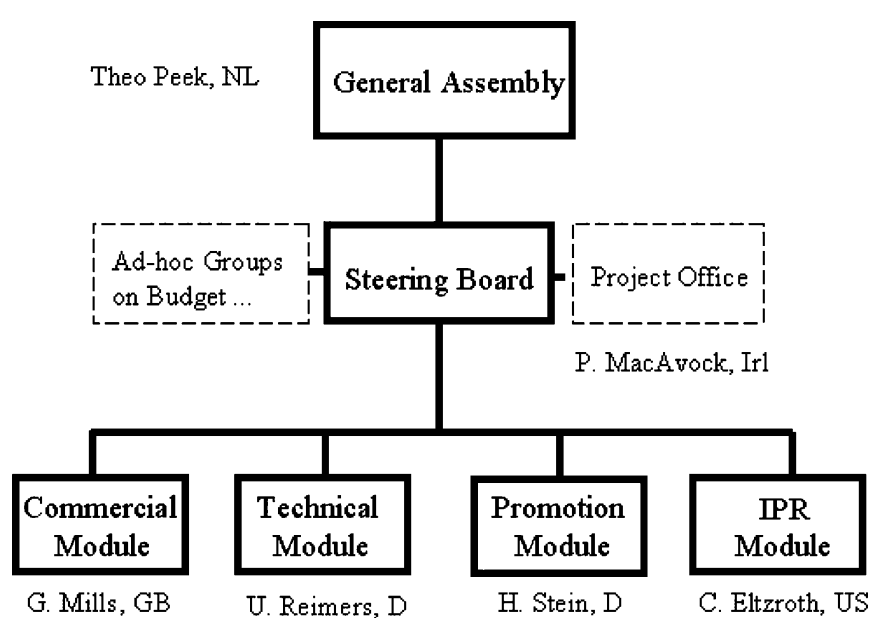

Fig. 7. Organizational chart of the DVB project (as of 2004).

2) Member organizations from countries outside of Europe are welcomed.

3) DVB operates on the basis of four constituencies bringing together content owners and broadcasters, network operators, manufacturers of hardware and software, and regulators.

4) Technical systems will only be developed by the DVB Technical Module if and when commercial requirements of such systems have been provided by the DVB Commercial Module and approved by the DVB Steering Board.

5) Every two years the strategy of DVB is to be revisited in order to be able to accommodate the changing nature of the world of electronic media.

Fig. 7 shows the current structure of the DVB Project. A more detailed look would reveal that currently 14 ad hoc groups are working inside the Technical Module.

The commercial working group (Commercial Module) of the DVB Project is responsible for the definition of commercial requirements for the new systems from the viewpoint of the users. These requirements form the basis of work within the Technical Module. After completion of the technical specification work, the Commercial Module verifies these specifications for the new systems and passes them on to the Steering Board for final decision. DVB does not standardize its own work, but passes its specifications to the ETSI and CENELEC standards institutes for integration into the regular standardization world.

At the time of the first activities on DVB in Europe, the Moving Pictures Experts Group (MPEG), a working group reporting to the ISO and IEC standardization institutions, which are active worldwide, was already working on a set of specifications for the source coding of video and audio signals and had already started the design of the respective systems level (MPEG-2). The proposed system known as MPEG Audio for the source coding of audio signals, in mono and stereo, was already in the final phase of standardization. The DVB Project decided that in order for the technological solution used by the DVB Project to find a wide international basis, DTV should be based on the MPEG standard. This decision led to an intensive cooperation between many $\mathrm{Eu}-$ ropean organizations and MPEG with the result that the research conducted in some places in Europe-with a different approach to image coding - was put aside in favor of a worldwide standard.

The first important result of the DVB Project emerged in late 1992, under the leadership of Professor Ulrich Reimers, one of the authors of this paper and later the chairman of DVB Technical Module. This was the report to the European Launching Group on the "Prospects for Digital Terrestrial Television," which was presented in November 1992 [36]. This report showed how, and with which aims, a European DVB system for Europe could be developed. The report was heavily weighted in favor of terrestrial transmission and toward HDTV as the probable quality objective. In this respect it was a product of its time and took into account the fact that, at the end of 1992, the official European development policy was still centered on the satellite and cable transmission of HD-MAC.

2) DVB Achievement and Ongoing Work: The first complete system specification was the recommendation for satellite transmission (DVB-S) adopted by the Technical Module in November 1993 [35]. In December 1993, the Steering Board agreed with this recommendation and in November 1994, by unanimous decision of all member states of ETSI, it became the European Telecommunications Standard ETS 300421 . In January 1994, the specification for DVB distribution via cable (DVB-C_-ETS 300 429) followed and since then numerous other specifications like DVB-T and DVB-H have been developed and adopted.

For many years, the DVB Project developed specifications addressing the technology of broadcast networks in order to transport digitized audio and video to TV receivers, set-top boxes, and high-fidelity audio receivers. Later, specifications for interactive channels were added. The completion of the specification for data broadcasting opened up DVB networks for the transmission of graphics, photos, and data-for example, by encapsulating Internet protocol (IP) based services in DVB data streams. At that time the users of personal computers and laptops started to take advantage of DVB services. The advent of the multimedia home platform (MHP) indicated another milestone, since with MHP software applications can be run on all sorts of terminal devices.

In December 2000, the DVB's General Assembly approved the milestone document "A Fresh Vision for a New DVB" [37]. It defines the foundations on which DVB was to embrace the challenges of convergence. The commercial and technical framework of this new structure was and will continue to be defined, based on the following vision: "DVB's vision is to build a content environment that combines the stability and interoperability of the world of broadcast with the vigor, innovation and multiplicity of services of the world of the Internet."

The ongoing development of the MHP is one of the key activities of the new DVB. Among other things, MHP can now be embedded in non-DVB digital broadcasting environments, like U.S. cable (OCAP), U.S. terrestrial (ACAP) and Japanese terrestrial DTV. Another significant new area for 


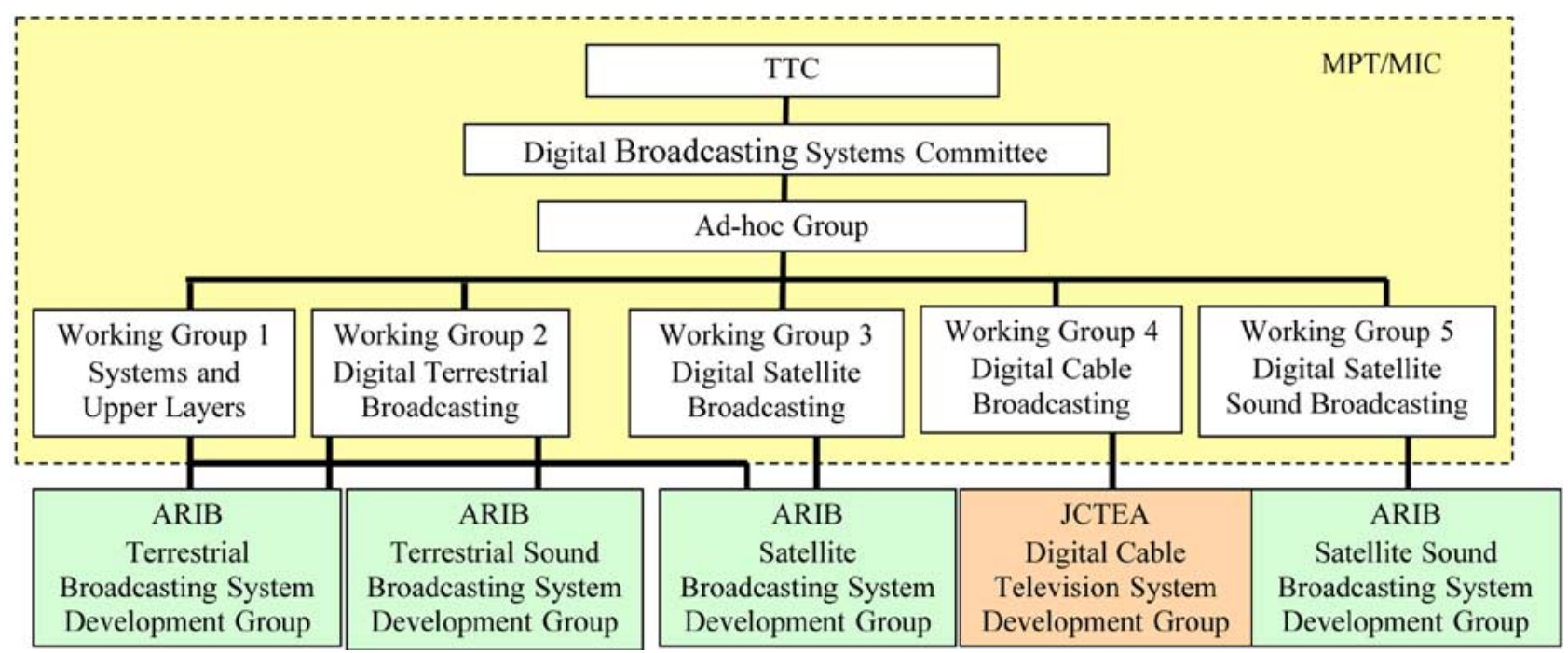

Fig. 8. Working structure of MPT/MIC and ARIB/JCTEA.

DVB is the development of specifications for the transport of "DVB content" over telecommunications networks (both fixed and mobile). A quite enlightening way of describing the technical activities within the Technical Module of the DVB Project is to list just a few of its $a d$ hoc groups: "Advanced Audio/Video Content Formats (for the transport of DVB content over IP-based networks)," "Convergence of Broadcast and Mobile Services (defining the technologies necessary to construct hybrid networks with a broadcast and a cooperating mobile telecommunications branch)," "Internet Protocol Infrastructures (for the efficient transport of DVB data streams over IP-based networks)," "Content Protection Technology (including copy management and rights management)," and "DVB-H (for the transmission of high-rate data streams to battery-powered personal communications devices)." After 12 years of work, the DVB Project is still extremely active in developing new solutions for the ever-changing world of the electronic media. At the time of writing (spring 2005), approximately 110 million DVB receivers (satellite, cable, and terrestrial) have been deployed.

\section{ISDB Process}

1) Working Structure: Japan has two layers of organization for broadcasting technology standardization. As shown in Fig. 8, the first layer is the Telecommunications Technology Council (TTC) of the Ministry of Internal Affairs and Communications (MIC) (this duty was performed by the former Ministry of Posts and Telecommunications (MPT). The second layer is the Association of Radio Industries and Businesses (ARIB). ARIB prepares reports on technical developments related to the work of the Digital Broadcasting Systems Committee of the TTC, and MIC approves these reports in order to formalize them for future administrative legislation. After the public notice of relevant legislation is given by MIC, ARIB prepares industrial standards (STD-B series) and technical reports (TR-B series) for digital broadcasting systems. In the case of cable television, the Japan Cable Television Engineering Association (JCTEA) fulfils the same role as ARIB. Both ARIB and JCTEA are now ITU-T Recommendation A.4/5 compliant organizations.

2) World's First HDTV Satellite Broadcasting Using $I S D B-S$ : With the aim of constructing a highly flexible, expandable digital broadcasting system, the NHK STRL launched its research project on ISDB in 1984. In 1993, ISDB research was approved as Question ITU-R 205/11 titled "Parameters for Integrated Services Digital Broadcasting (ISDB)." A variety of research on ISDB was then carried out to develop such broadcasting systems for satellite, terrestrial, and cable channels.

The Radio Regulatory Council in Japan issued a report in May 1997 on the introduction of BS digital broadcasting, which operates under the 12-GHz WARC-BS planned band. The decision to go with this system led to the launch of BS digital broadcasting services in 2000. BS has been developed as a completely new broadcasting system based on ISDB and focusing on HDTV.

BS digital broadcasting uses a completely new transmission mechanism as the ISDB system for satellite distribution. It consists of 1080 effective scanning lines (interlaced) as the video input format for the MPEG-2 HP@ML video source coding and up to 5.1-channel audio signals for the MPEG-2 AAC audio coding. The BS digital broadcasting system can provide a data transmission rate of more than $52 \mathrm{Mb} / \mathrm{s}$ within a bandwidth of $34.5 \mathrm{MHz}$. The transmission scheme became Recommendation ITU-R BO.1408 under the name of ISDB-S in 1999 and has since become an international standard system. The major broadcasters in Japan have been broadcasting seven HDTV programs via direct BS channels since December 2000. There were 7.8 million subscribers all over Japan at the end of January 2005.

3) Flexible Digital Terrestrial Broadcasting Services Using ISDB-T System: With regard to a transmission scheme for digital terrestrial broadcasting, studies on orthogonal frequency division multiplexing (OFDM) modulation technique, started in 1986, resulted in experiments on transmitting video signals to mobile terminals in 1992. 
Other developments occurred in 1994, when the TTC took up a digital terrestrial broadcasting feasibility study.

To accelerate the development of a transmission scheme for digital terrestrial broadcasting, MPT established an advanced digital broadcasting system development consortium in 1995 named DTV-Lab. This entity consisted of NHK, major commercial broadcasters, and five leading broadcasting-related equipment manufacturers. In 1996, the Digital Terrestrial Broadcasting System Development Group was set up by ARIB. Another ARIB development group was set up to deal with digital terrestrial sound broadcasting in 1998, beginning with the development of a system that would work alongside the digital terrestrial television system.

These digital terrestrial broadcasting systems were presented in a technical report to the TTC in 1999, followed by large-scale collaborative experiments for six months, using the Tokyo Tower transmission facility that covers the Tokyo metropolitan area. They were approved as System C of Recommendation ITU-R BT.1306 in 2000.

Digital terrestrial television broadcasting services began in December 2003 in the Tokyo, Osaka, and Nagoya areas. The expansion of the services to the entire nation is to be completed by 2006. In addition, digital terrestrial sound broadcasting services began in October 2003 in the Tokyo and Osaka areas.

4) Digital Transmission Systems Over Cable Television Networks: ISDB services have already been offered over cable television networks in Japan. Cable television networks retransmit communication satellite (CS) digital broadcasting services. This system was established using the 64-QAM modulation scheme in 1996 by TTC and JCTEA. Through ITU-T Study Group 9 standardization activity, this system became a part of ITU-T Recommendation J.83, which was approved in 1997.

Transmodulation and pass-through systems have been developed for retransmission of terrestrial digital broadcasting services. The transmodulation system converts the PSK (satellite) or OFDM (terrestrial) modulation schemes of radio broadcast signals into 64 QAM. The system can carry multiple MPEG-2 Transport Streams on a single carrier. It has been used at more than 100 cable television facilities to retransmit ISDB-S signals, while more than ten cable television facilities retransmit all digital broadcasting services including ISDB-T.

The pass-through system retransmits radio digital broadcasting services over cable without changing their modulation schemes. The frequencies of the signals may be changed, if the frequency of the original signal is higher than that of the cable facility's upper frequency limit. This satisfies the requirement of retransmission of terrestrial broadcasting signals, because the channel bandwidth of terrestrial broadcasting is the same as that of the cable television system.

Using these methods, digital broadcasting services have been implemented by a number of cable television operators, and cable subscribers currently enjoy digital broadcasting services that include retransmission of ISDB-T, ISDB-S, and CS broadcasting.
5) World's First Handheld Reception of Digital Sound Satellite Broadcasting Services: A digital satellite sound broadcasting system was developed and standardized in TTC and ARIB in 1998 and 1999, based on the proposal made by Toshiba Corporation. Right after the final approval by TTC in 1999, this system was proposed to ITU-R Joint Working Party 10-11S (former Working Party 6S) for satellite broadcasting. In July 2000, it became Digital System E of Recommendation ITU-R BO.1130.

This system is designed to provide satellite and complementary terrestrial on-channel repeater services providing high-quality audio and multimedia data for vehicular, portable, and fixed reception. It has been designed to optimize the performance of satellite and terrestrial on-channel repeater services in the $2.6-\mathrm{GHz}$ band. This is achieved through the use of code division multiplex (CDM) based on QPSK modulation with concatenated Reed-Solomon and convolutional error correcting codes. The system provides not only sound programs, but also video streaming, multimedia services, and data broadcasting.

This system is now providing the world's first broadcast satellite service (BSS) sound broadcasting that can be received by handheld receivers, equipped with a 3.5 -in LCD screen. The special broadcasting satellite MB-Sat was launched in March 2004, and the commercial broadcasting service began in October 2004.

\section{CONCLUSION}

We have introduced the history and migration paths of current DTV systems. The DTV systems that are now available around the world not only deliver crystal-clear pictures and CD-quality sound, but they also provide various innovative new services and programs, such as electronic program guide, personalized advertisements, parental control, conditional access, emergency alerts, software download, IP encapsulation, data broadcasting, various interactive services. DTV also provides a seamless interface with other communication systems, computer networks, and digital media, and can even be used to deliver content to handheld devices. The introduction of DTV will increasingly impact broadcasters, consumers, and many related industries.

The bulk of this special issue on DTV comprises three special sections of papers providing detailed information on the ATSC, DVB, and ISDB systems and related standards. There is also a paper entitled "Digital Television Station and Network Implementation" covering practical issues faced by broadcasters around the world as they have transitioned from analog to digital technologies-both for transmission and for program production.

\section{ACKNOWLEDGMENT}

The authors would like to thank W. Bretl of Zenith Electronics and A. Magoun of Sarnoff Library for their contribution of the "blue banana" story. The authors would also like to thank Dr. I. Childs of BBC, D. Sauvet-Goichon of TDF, Dr. H. Katoh of NHK, and G. Reitmeier of NBC for providing historical photos. The authors would like to acknowledge the help and advice from G. Jones, NAB Science and 
Technology, and P. MacAvock of DVB in developing this manuscript.

\section{REFERENCES}

[1] "Broadcasting pioneers: The many innovators behind television history " [Online]. Available: http://inventors.about.com/library/inventors/bltelevision.htm

[2] "Television history—The first 75 years" [Online]. Available: http:// www.tvhistory.tv/

[3] D. G. Fink, "Perspectives on television: The role played by the two NTSC's in preparing television service for the American public," Proc. IEEE, vol. 87, no. 9, pp. 1672-1681, Sep. 1999.

[4] "First report of commission (color television issues)," FCC Dockets 8736, 8975, 8976, and 9175, Sep. 26, 1949.

[5] J. Udelson, The Great Television Race: A History of the American Television Industry, 1925-1941. Tuscaloosa, AL: Univ. Alabama Press, 1982.

[6] "A six-megacycle compatible high-definition color television system," RCA Rev. vol. 10, pp. 504-522, Dec. 1949.

[7] "Report and order of Federal Communications Commission," Washington, DC, FCC Doc. 53-1663, Dec. 17, 1953.

[8] G. H. Brown, And Part of Which I Was. Princeton, NJ: Angus Cupar, 1982, pp. 225-226.

[9] D. H. Pritchard and J. J. Gibson, "Television transmission standards," in Standard Handbook of Broadcast Engineering, J. C. Whitaker, Ed. New York: McGraw-Hill, 2005, pp. 3.9-3.33.

[10] Y. Ninomiya, "The Japanese scene," IEEE Spectr., vol. 32, no. 4, pp. 54-57, Apr. 1995.

[11] B. Fox, "The digital dawn in Europe [HDTV]," IEEE Spectr., vol. 32 , no. 4, pp. 50-53, Apr. 1995.

[12] R. J. G. Ellis, The PALplus Story. Manchester, U.K.: Architects' Publishing Partnership Ltd., 1997.

[13] M. A. Isnardi, T. Smith, and B. J. Roeder, "Decoding issues in the ACTV system," IEEE Trans. Consum. Electron., vol. 34, no. 1, pp. 111-120, Feb. 1988.

[14] T. Fujio, "High definition television," NHK Tech. Monograph 32, Jun. 1982.

[15] R. K. Jurgen, "Chasing Japan in the HDTV race," IEEE Spectr., vol. 26, no. 10, pp. 26-30, Oct. 1989.

[16] N. Hatori and M. Nakamura, "1125/60 HDTV studio standard intended to be a worldwide unified HDTV standard," IEEE Trans. Broadcast., vol. 35, no. 3, pp. 270-278, Sep. 1989.

[17] R. Hopkins and K. P. Davis, "Development of HDTV emission systems in North America," IEEE Trans. Broadcast, vol. 35, no. 3, pp. 259-269, Sep. 1989.

[18] A. P. Cavallerano, "System and technological details of terrestrial/ cable NTSC compatible HDTV," IEEE Trans. Consum. Electron. vol. 35, no. 3, pp. 227-23, Aug. 1989.

[19] A. C. Sikes, FCC Commissioner, "Speech to Advisory Committee," Jan. 1990.

[20] W. Paik, "DigiCipher-all digital, channel compatible, HDTV broadcast system," IEEE Trans. Broadcast., vol. 36, no. 4, pp. 245-254, Dec. 1990.

[21] J. A. Krauss, "Source coding, channel coding and modulation techniques used in the DigiCipher system," IEEE Trans. Broadcast., vol. 37, no. 4, pp. 158-161, Dec. 1991.

[22] G. A. Reitmeier, C. Basile, and S. A. Keneman, "Source coding, channel coding and modulation techniques used in the ADTV system," IEEE Trans. Broadcast., vol. 37, no. 4, pp. 166-169, Dec. 1991.

[23] K. Joseph, S.-B. Ng, R. Siracusa, D. Raychaudhuri, J. Zdepski, and R. Saint Girons, "Prioritization and transport in the ADTV digital simulcast system," IEEE Trans. Consum. Electron., vol. 38, no. 3, pp. 319-324, Aug. 1992.

[24] W. C. Luplow and P. Fockens, "Source coding, channel coding and modulation techniques used in the digital spectrum-compatible HDTV system," IEEE Trans. Broadcast., vol. 37, no. 4, pp. 162-165, Dec. 1991

[25] J. Lim, P. Monta, J. Nicolas, J. Apostolopoulos, S. Cheung, W. Paik, E. Krause, and V. Liu, "Channel-compatible Digicipher HDTV System," in Proc. IEEE Int. Conf. Consumer Electronics 1992, pp. $140-141$.

[26] W. Y. Zou, "Comparison of proposed digital HDTV terrestrial broadcasting systems," IEEE Trans. Broadcast., vol. 37, no. 4, pp. 145-147, Dec. 1991
[27] T. E. Bell, "The HDTV 'test kitchens'," IEEE Spectr., vol. 32, no. 4, pp. 46-49, Apr. 1995.

[28] C. W. Rhodes, "Testing of proposed ATV systems," in Proc. IEEE Int. Conf. Consumer Electronics 1990, p. 74.

[29] B. Caron, "Facility for subjective evaluation of advanced television in North America," in Proc. 4th Int. Conf. Television Measurement, 1991, pp. 6-12.

[30] ATSC system recommendation Advisory Committee on Advanced Television Service, Federal Communications Commission, Washington, DC, Feb. 23, 1993.

[31] R. Hopkins, "Progress on HDTV broadcasting standards in the United States," Advanced Television Systems Committee, Washington, DC, Dec. 1993.

[32] K. Challapali, X. Lebegue, J. S. Lim, W. H. Paik, and P. A. Snopko, "The Grand Alliance system for US HDTV," Proc. IEEE, vol. 83, no. 2, pp. 158-174, Feb. 1995.

[33] R. Hopkins, "Choosing an American digital HDTV terrestrial broadcasting system," Proc. IEEE, vol. 82, no. 4, pp. 554-563, Apr. 1994.

[34] "Advisory Committee Final Report and Recommendation," Advisory Committee on Advanced Television Service, Federal Communications Commission, Washington, DC, Nov. 28, 1995.

[35] U. Reimers, DVB-The Family of International Standards for Digital Video Broadcasting. Berlin, Germany: Springer, 2004.

[36] — - "European perspectives on digital television broadcasting - conclusions of the Working Group on Digital Television Broadcasting (WGTB)," EBU Tech. Rev., no. 256, Summer, 1993.

[37] The DVB Project, "A fresh vision for a new DVB," [Online]. Available: http://www.dvb.org/index.php?id=20

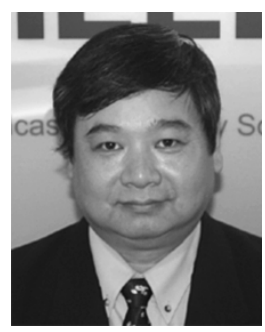

Yiyan Wu (Fellow, IEEE) received the B.Eng degree from the Beijing University of Posts and Telecommunications and the M.Eng. and Ph.D. degrees in electrical engineering from Carleton University, Ottawa, Canada, in 1986 and 1990, respectively.

After graduation, he worked at Telesat Canada as a Senior Satellite Communication Systems Engineer. In 1992, he joined Communications Research Centre Canada (CRC), Ottawa, ON, and is now a Principal Research Scientist. He is also an Adjunct Professor with Carleton University, Ottawa; Shanghai Jiaotong University; and Beijing University of Posts and Telecommunications. He has more than 200 publications. His research interests include broad-band multimedia communications, digital broadcasting, and communication systems engineering.

Dr. Wu is a member of the IEEE Broadcast Technology Society Administrative Committee, and a member of the ATSC Board of Directors, representing IEEE. He is the Editor-in-Chief of the IEEE T RANSACTIONS ON B ROADCASTING. He has received many technical awards for his contribution to the research and development of digital broadcasting and broad-band multimedia communications.

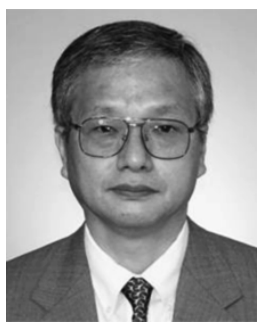

Shuji Hirakawa (Fellow, IEEE) received the Ph.D. degree from the University of Tokyo, Tokyo, Japan, in 1978.

He joined Toshiba Corporation, Tokyo, in 1978. In the late 1980s and early 1990s, he was deeply involved in the development of the MUSE encoder for HDTV transmission. From 1998, his group developed a new broadcasting satellite service (BSS) system for digital sound broadcasting and was adopted by Japanese industrial standardization body (ARIB) as a domestic standard. With ITU-R, he developed Recommendation BO.1130 System E for Japanese BSS (sound) in 1999 and 2000.

Dr. Hirakawa is also a key member in many international standardization organizations. Currently, he is a vice-chairman of ITU-R WP 6M (Multimedia and Interactive broadcasting system) and the secretary of IEC TC 100 (Audio, Video and Multimedia Systems and Equipment). His pioneering research on "coded modulation" as a Ph.D. student was published in a paper coauthored with Prof. H. Imai ("A new multilevel coding method using error-correcting codes," IEEE Trans. Inform. Theory, vol. IT-23, no. pp. 371-377, May 1977), which was selected as one of 17 papers to receive the 
IEEE Golden Jubilee Paper Award in 1998. He is an Associate Editor of the IEEE TRANSACTIONS ON BROADCASTING, and he has been the Secretary of IEEE Broadcast Technology Japan Chapter since 2002.

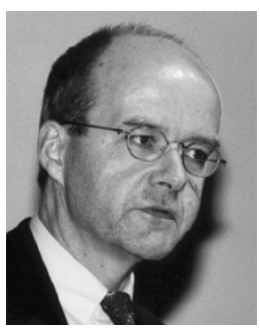

Ulrich H. Reimers (Senior Member, IEEE) studied communication engineering at Technische Universitaet Braunschweig Braunschweig Technical University), Germany.

Following research at the University's Institut fuer Nachrichtentechnik (Institute for Communications Technology) he joined BTS Broadcast Television Systems, Darmstadt, Germany. Between 1989 and 1993 he was Technical Director of Norddeutscher Rundfunk (NDR), Hamburg-one of the major broadcasters in Germany. Since 1993, he has been a Professor at Technische Universitaet Braunschweig, Braunschweig, Germany, and Managing Director of the Institut fuer Nachrichtentechnik (Institute for Communications Technology). $\mathrm{He}$ is the author of more than 100 publications, including various textbooks on DVB.

Prof. Reimers is Chairman of the Technical Module within the DVB Project and a Board Member of Deutsche TV-Plattform (the German institution coordinating the interests of all organizations involved in TV). $\mathrm{He}$ has received numerous international technical awards for his contribution to the development of digital broadcasting.

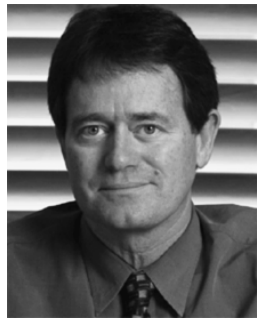

Jerry Whitaker (Member, IEEE) is the Vice President for Standards Development of the Advanced Television Systems Committee (ATSC). He supports the work of the various ATSC technology and planning committees and assists in the development of ATSC standards and related documents. He currently serves as Secretary of the Technology and Standards Group and Secretary of the Planning Committee, and is closely involved in work relating to educational programs. He is the author and editor of more than 35 books on technical topics, including The Standard Handbook of Video and Television Engineering, 4th ed. (McGraw-Hill, 2003); NAB Engineering Handbook, 9th ed. (National Association of Broadcasters, 1999), DTV Handbook, 3rd ed. (McGraw-Hill, 2001), and The Electronics Handbook, 2nd ed (CRC, 2005). Prior to joining the ATSC, he headed the publishing company Technical Press, Morgan Hill, CA.

Mr. Whitaker is a Fellow the Society of Broadcast Engineers and a Fellow of the Society of Motion Picture and Television Engineers. He has served as a Board member and Vice President of the Society of Broadcast Engineers. 